\title{
A RELAÇÃO TRANSMISSIBILIDADE DA DOENÇA CÁRIE ENTRE MÃES E SEUS FILHOS ADOTIVOS
}

\section{THE TRANSMISSIBILITY RELATION OF DENTAL CARIES BETWEEN MOTHERS AND THEIR ADOPTED CHILDREN}

\author{
Márcia Cançado Figueiredo ${ }^{1}$, Isolda Cerqueira Cruz ${ }^{2}$, Page William Caufield ${ }^{3}$ \\ 1 Autor para contato: Universidade Federal do Rio Grande do Sul, Faculdade de \\ Odontologia, Porto Alegre, RS, Brasil;(51)3337-5471; e-mail: marciacf@myway.com.br \\ 2 Governador Valadares, Minas Gerais, Brasil \\ 3 New York University, USA
}

Recebido para publicação em 30/08/2004

Aceito para publicação em 16/12/2004

\section{RESUMO}

Microrganismos denominados "estreptococos do grupo mutans" (S mutans) são os principais responsáveis pelo desenvolvimento da cárie dentária em humanos e colonizam na cavidade bucal de crianças após a irrupção dos primeiros dentes. A transmissão ocorre por meio da saliva, sendo a mãe a principal fonte de transmissão para seus filhos. Objetivou-se neste estudo avaliar a relação transmissibilidade da cárie entre 25 pares: mães/filhos naturais (G1) e mães/filhos adotivos (G2). O indice de cárie CPOS modificado foi empregado nos grupos G1 e G2, bem como um questionário fechado sobre os hábitos alimentares praticados pelas mães durante o período da “janela de infectividade”. Na avaliação dos genótipos de $S$. mutans utilizou-se a técnica da reação em cadeia da polimerase (PCR), como recomendado na literatura. Os resultados mostraram que nos pares mães/filhos adotivos preponderaram genótipos de $S$. mutans diferentes, sugerindo que a transferência deste microorganismo é mesmo materna. Como resultados observou-se que a transmissibilidade deste microrganismo por meio dos hábitos alimentares não diferiu muito, obviamente que apenas as mães naturais amamentaram seus filhos no seio. O índice de cárie dos filhos adotivos foi baixo $(<25 \%$ de superfícies cariadas) o que permite concluir que a mãe é a principal fonte de transmissão do $S$. mutans, uma vez que os filhos adotivos possuiam cepas de $S$. mutans diferentes aos de suas mães adotivas. Esse fato pode justificar esta baixa prevalência de cárie presente nas crianças adotivas. Como buscamos a prevenção da doença cárie, por que não sugerir a introdução de cepas não-maternas de $S$. mutans e/ou outras não cariogênicas que sejam menos virulentos antes do início da irrupção dos primeiros dentes decíduos na cavidade bucal de um bebê? 
Palavras-chave: transmissibilidade da doença cárie, microorganismos cariogênicos, filhos adotivos - mães

\begin{abstract}
Microorganisms called $S$. mutans are some of the main agents responsible for the development of dental caries in humans, and they colonize the children's oral cavity after the irruption of the deciduous teeth. SM is transmitted through the saliva, and the main transmission agent for the children is their mother. The purpose of this study was to evaluate the transmissibility relation of dental caries among 25 pairs: mothers/natural children (G1) and mothers/adopted children (G2). The DMFS modified caries index was employed in G1 and G2, as well as a closed questionnaire about these mothers' diets during the caries "infectivity window" of their children. As suggested in the literature, the polimerase reaction technique (PCR) was used to evaluate the mutans genotype. The results showed that in the pair of mothers/adopted children the genetic characteristics of $S$. mutans were different, which suggested that the transmission of the bacteria really occurred through the mother. The diet transmissibility did not differ, and obviously, only the natural mothers breast-fed their children. The caries index in the adopted children was low ( $<25 \%$ of carious surfaces). The results of the study demonstrated that the mother was the main transmission agent of the genetic characteristics of $S$. mutans, for the adopted children had different SM from their adoptive mothers. This fact could justify the low prevalence of caries in the adopted children. As we look for the prevention of caries, why not suggest the introduction of genetic characteristics of non-maternal S. mutans and/or other microorganisms which have a less strong evidence of virulent microbial genetic components in the etiology of carious disease, before the beginning of the eruption of the first deciduous teeth in a baby's oral cavity?
\end{abstract}

Key words: transmissibility of caries disease, cariogenics microrganisms, adopted children - mothers

\section{Introdução}

A cárie é presentemente reconhecida como uma doença infecto-contagiosa, que resulta na perda localizada de minerais dos dentes afetados causada por ácidos provenientes da fermentação microbiana dos carboidratos da dieta (Weyne, 1989).

Pode-se atribuir à doença cárie um caráter multifatorial, sendo esta terminologia usada para explicar a interação entre três fatores etiológicos primários equipotentes e essenciais para a sua iniciação e progressão (o hospedeiro suscetível - o dente; uma microbiota cariogênica - os estreptococos do grupo mutans principal patógeno do desenvolvimento da doença cárie; e um adequado substrato local - a sacarose) (Keyes,1962).

A certeza da participação de microorganismos no desenvolvimento dessa doença já vem sendo descrita há mais de dois séculos. Esses microorganismos são específicos para essa doença, fazendo com que a placa bacteriana de natureza cariogênica seja constituída de uma microbiota anaeróbica, Gram positiva, sacarolítica e representada basicamente pelos estreptococos do grupo mutans. Como confirmado por Loesche em 
1977, os S. mutans são microorganismos altamente cariogênicos e a sua aquisição se faz presente nas fases precoces da vida, ou seja, logo após a erupção dos dentes. Também se sabe que sua colonização tem predileção por dentes cuja anatomia é rica em áreas retentivas, como descrito por Weyne em 1989.

Os trabalhos de Alaluusua; Renkonen, 1983; Berkowitz; Jordan, 1975; Caufield,1993, 1995, 1999; Fitzgerald; Keyes,1960; Keyes, 1960, 1962; Köhler et al.,1982, 1983 e 1985; Thibodeau, 1993, confirmaram ser a cárie uma doença infecciosa transmissível, sendo o fator transmissibilidade essencial para a sua instalação e seu desenvolvimento.

Estudos transversais utilizando meios de bacteriocina, sorotipagem ou genotipagem, sugeriram que as mães são as principais fontes de aquisição/transmissão dos estreptococos do grupo mutans para seus filhos, e que esta se daria através do contato direto da saliva da mãe com a saliva de seu filho. A aquisição/ transmissão dos estreptococos do grupo mutans é proporcional ao nível destes microorganismos cariogênicos presentes na saliva da mãe (Konönen et al. em 1992).

Esta afirmativa deixa a dúvida de como se daria esta aquisição/transmissão dos estreptococos do grupo mutans, no caso de filhos que foram adotados antes de se abrir a sua $1^{\circ}$ JANELA DA INFECTIVIDADE DA CÁRIE DENTÁRIA. Sendo a adoção uma prática comum no Brasil e, estando esta definida, pela Lei Federal 8.069/90, o Estatuto da Criança e do Adolescente (Neves,1996), foi possível realizar um estudo que permitisse avaliar a fidelidade de transmissão do S.mutans entre as mães e seus respectivos filhos adotivos, através da identificação dos genótipos de algumas amostras de estreptococos do grupo mutans isoladas da cavidade bucal de mães e filhos adotivos. Foi também realizada a avaliação dos índices de cárie (CPOS modificado e ceos modificado) das mães e de seus respectivos filhos adotivos e naturais e dos hábitos relacionados à dieta, higiene bucal e ao comportamentos dos filhos adotivos e naturais, durante o período da janela da infectividade da cárie.

O estreptococos do grupo mutans é aparentemente difícil de se transmitir fora da teórica janela de infectividade durante a infância (Caufield et al., 1993). É realmente tentador especular que uma criança que adquire estreptococos do grupo mutans de uma fonte outra que não a sua mãe natural pode ser menos propensa a ter cárie!

\section{Revisão de literatura}

Sendo a cárie uma doença multifatorial, uma dieta rica em carboidratos fermentáveis serve de substrato para os microorganismos cariogênicos produzirem ácidos orgânicos que atuarão na superfície dentária, com maior ou menor intensidade, dependendo da suscetibilidade do hospedeiro. A existência de fatores secundários (saliva, flúor e higiene bucal) e terciários (sexo, idade, raça e nível sócio-econômico) também têm grande influência no desenvolvimento da cárie dentária, funcionando como moduladores e influenciadores dos fatores primários, respectivamente (Araujo, F.B.; Figueiredo, M.C,1997).

A certeza da participação de microorganismos no desenvolvimento da cárie já vem sendo descrita há mais de dois séculos. Existem, então, microorganismos específicos relacionados à cárie, fazendo com que a placa bacteriana de natureza cariogênica seja constituída de uma microbiota anaeróbica, Gram +, sacarolítica e representada basicamente pelos $S$. mutans. Estreptococos mutans constituem um grupo heterogêneo de microorganismos, atualmente denominado estreptococos do grupo mutans (Maltz; Carvalho,1997). Como confirmado por Loesche em 1977, os S. mutans são microorganismos altamente cariogênicos e a sua aquisição se faz presente nas fases precoces da vida, logo após a erupção dos dentes. Os $S$. mutans são os microorganismos mais relacionados com a cárie dental em humanos por possuirem as seguintes características: capacidade de colonizar os dentes, produzirem polissacarídeos intra e extracelulares, serem altamente acidogênicos e acidúricos e metabolizarem várias glicoproteínas salivares (Maltz; Carvalho,1997).

Quanto ao fato de ser a doença cárie transmissível, foi Keyes em 1960, que pela primeira vez levantou a possibilidade dessa transmissão ser interindividual, ao constatar em um estudo experimental realizado em hamsters que filhotes cárie-resistentes poderiam ser contaminados quando engaiolados com animais cárie-ativos.

Posteriormente, novas pesquisas surgiram, 
demonstrando que esta transmissibilidade ocorreria em humanos predominantemente da mãe para o filho, através do contato físico direto (Van Houte et a.l,1981, Rogers,1981, Berkowitz; Jones, 1985, Masuda et al.,1985, Kulkarui et al.,1989, Caufield; LI; DasanaYake,1993, Caufield et. al.,1995). Outros experimentos confirmaram que a mãe é a maior fonte de infecção do $S$. mutans para seus filhos. Esse fato foi demonstrado através da similaridade de perfis de $S$. mutans isolados de mães e filhos, ou seja, mães com altos ou baixos níveis de $S$. mutans tendem a ter filhos com os mesmos níveis salivares desse micro-organismo, respectivamente (Berkowitz; Jordan, 1975, Davey; Rogers,1984).

Podemos dizer que, a imunidade está relacionada de uma forma direta a essa transmissibilidade entre mãe - filho visto que, Caufield et al.,1993 demonstraram que a metade das crianças por eles estudadas, entre as idades de 1 a 2 anos que não foram contaminadas pelo $S$. mutans, eram cuidadas por outras pessoas que não as suas próprias mães, enquanto que, todas as crianças cárie-ativas, durante o mesmo período eram cuidadas por suas mães. Ainda é interessante ressaltar que a colonização do $S$. mutans na cavidade bucal de crianças confirma ser a saliva materna o principal veículo de transmissão, sendo a intensidade desta, proporcional ao nível desses micro-organismos na saliva materna. Esses mesmos autores denominaram o período que vai dos 19 aos 31 meses de idade, com média de 26 meses, a JANELA DA INFECTIVIDADE DA CÁRIE DEN-

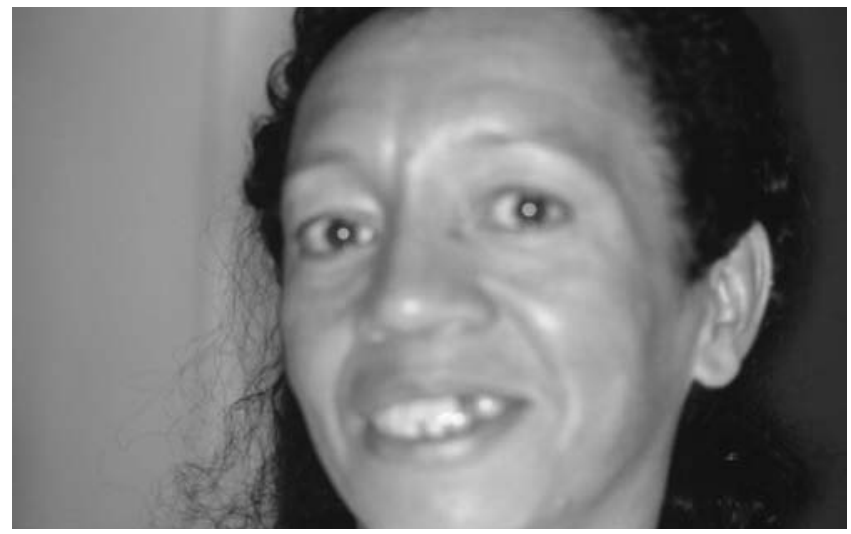

TÁRIA na dentição decídua, procurando relacionar com o fato das mães desfrutarem de freqüentes e íntimos contatos com seus filhos nesse período.

Não queremos dizer com isso que a transmissão desses microorganismos também não se dê de forma indireta, ou seja, por meio de alimentos ou objetos contaminados. Segundo Köhler; Bratthall,1978 os $S$. mutans podem sobreviver de maneira viável nos objetos expostos ao meio ambiente por 7 horas, sendo, portanto, ainda passíveis de transmissão. Também Svanberg,1978, em outro estudo, demonstrou que as escovas dentais podem apresentar-se altamente contaminadas pelo $S$. mutans após o seu uso e assim permanecer por algum tempo, podendo assim servir de meio de transmissão interindividual da doença.

Como um reforço da hipótese de ser a cárie uma doença transmissível de mãe para filho, outros estudos demonstraram uma relação positiva entre a experiência de cárie da mãe e a de seu filho, sugerindo deste modo que um bom preditor do risco de cárie de uma criança seja o valor do C PO S modificado de sua mãe. Também, Tuuti et al.,1989 e Figueiredo et al.,1996 observaram uma relação positiva entre a experiência de cárie das mães e a de seus filhos. (Fotos 1,2,3,4,5 e 6). Tanto que Alaluusua; Renkonen,1983 relevam a importância de se orientar as mães sobre os meios de infecção da doença cáriee sugerem que todas as medidas preventivas adotadas nas mães refletirão na ausência ou no retardo da infecção dos seus filhos pelos $S$. mutans.

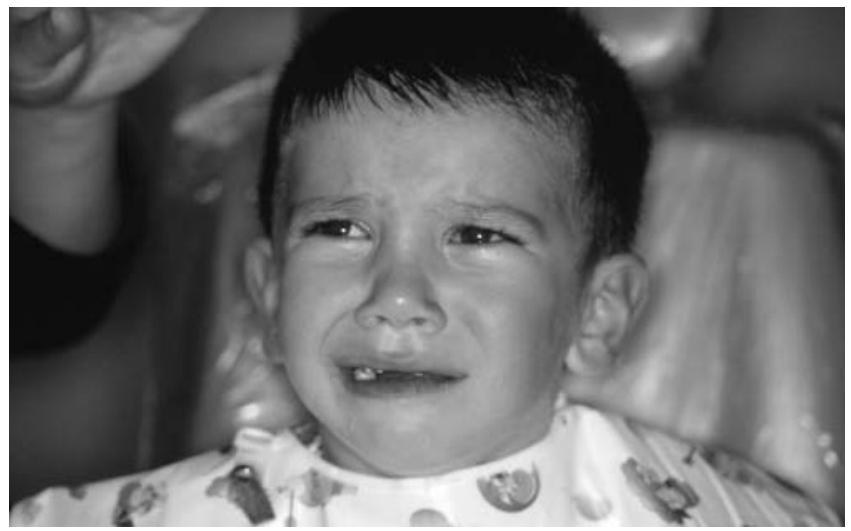

Figuras 1 e 2 - Foto de uma mãe e seu filho de 3 anos e 8 meses com facie de dor por ser portador da cárie precoce da infância -ECC. 

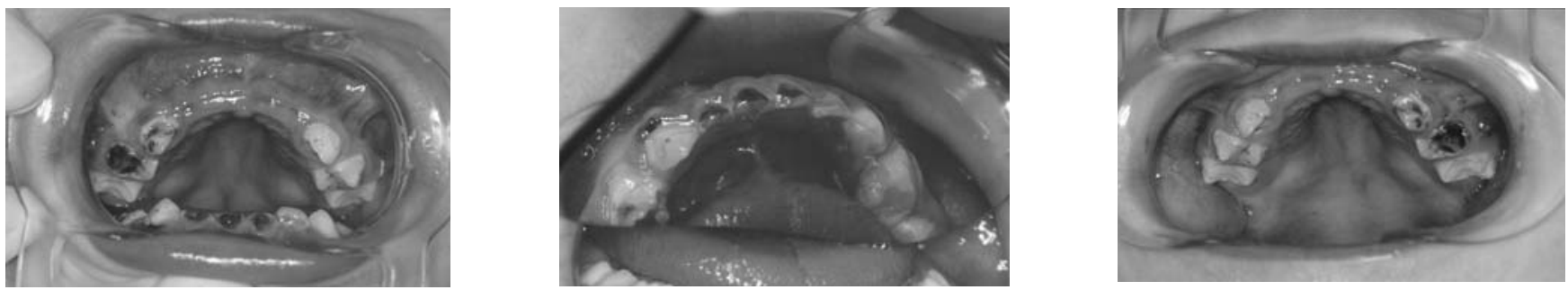

Figuras 3, 4 e 5 - Aspecto clínico da cavidade bucal do filho destacando as arcadas inferiores e superiores.

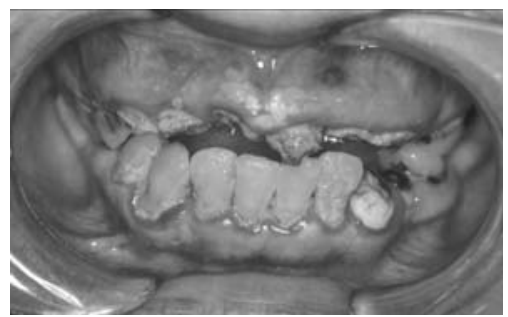

Figura 6 - Aspecto clínico da cavidade bucal da mãe com presença de inúmeras lesões cariosas e biofilme organizado.

Vários estudos como os de Alaluusua et al., 1989; Berkowitz; Jordan, 1975, Berkowitz; Jordan, 1985, Caufield et al., 1988; Caufield; Li; Dasanayake,1993, Caufield,1995, Dayed; Rogers, 1984, Kulkarni et al.,1989, Rogers, 1981, Van Houte et al.,1981, mostraram, por distintos meios, serem as mães as principais fontes de infecção/ transmissão para os seus filhos.

O termo fidelidade de transmissão foi utilizado por Caulfield et al. em 1995, para designar o grau de semelhança entre o genótipo de estreptococos mutans isolados de pares de mães e filhos. Por exemplo, se espécies de estreptococos mutans isoladas de mães e filhos apresentassem o mesmo genótipo, os autores consideravam esse valor como $100 \%$ de fidelidade de transmissão. Ao contrário, se não houvesse semelhança entre os estreptococos mutans isolados dos pares mãe-filhos, os autores consideravam como $0 \%$ de fidelidade. Baseado nessas informações, este autor demostrou que, 70\% dos pares mãe-filhos apresentaram estreptococos mutans genotípicamente semelhantes e 30\% desses pares, não possuíam estreptococos mutans genotipicamente semelhantes.

\section{Materiais e Métodos}

Foi selecionado um grupo de 18 mães de idades variando entre 20 e 60 anos, que adotaram seus filhos antes de eles completarem 6 meses de idade, ou seja, antes de terem os seus primeiros dentes decíduos em boca. Esses pares de mães e filhos foram identificados como PAR 01 até PAR 18, sendo que três pares tinham gêmeos adotivos e quatro pares, após a adoção, tiveram os seus filhos naturais. A amostra constituiu-se de 18 mães, 31 filhos adotivos e 4 naturais. Todas as mães concordaram em participar do estudo, assinando um termo de consentimento prévio. A coleta dos dados e do material para ser analisado foi realizada no consultório particular da Dra. Isolda Cerqueira Cruz, na cidade de Governador Valadares, localizada ao norte do estado de Minas Gerais.

Inicialmente foi aplicado um questionário às mães de forma a obter dados específicos sobre os hábitos relacionados à dieta e à higiene bucal de seus filhos adotivos e os quatro filhos naturais, durante o período da janela da infectividade da cárie. 


\section{Questionário}

\section{Identificação do Par:}

Filho no

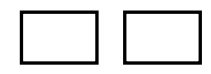

Nome da Mãe:

Nome do Filho (a):

Idade do Filho (a):

Anos

Adotivo ( ) Natural ( )

Número de Irmãos: Meses

\section{Perguntas}

1- Seu Filho foi amamentado?

( ) Natural ( ) Artificial ( ) Ambos

2- Até quando foi amamentado?

( ) Até 3 meses ( ) Até 6 meses ( ) Até 12 meses ( ) Mais que 12 meses

3- Qual a freqüência de amamentação?

( ) Até 3 vezes ao dia ( ) Mais que 3 vezes ao dia

4- Adoçava a mamadeira de seu filho?

( ) Não ( Sim,com Açúcar ( ） Sim,com adoçante artificial ( ) Sim,com mel

5- Seu filho utilizou a mamadeira noturna?

( ) Não( ) Sim

6- Após as mamadas de seu filho você fazia algum tipo de higienização bucal?

( ) Nenhuma ( ) Sim, com Fralda ( ) Sim, com Gaze

7- Seu filho teve contato com o Flúor?

( ) Não ( ) Sim, água de abastecimento ( ) Sim, dentifrício ( ) Sim, bochecho

( ) Sim, todos acima mencionados

8- Que Hábitos você praticava quando seu filho era bebê:

( ) Experimentar o alimento de seu filho

( ) Soprar o alimento de seu filho

( ) Beijar na boca de seu filho

( ) Limpar o bico do seu filho com a própria boca

( ) Adoçava a chupeta com mel ou açúcar

( ) Todos acima descritos

A avaliação do índice de cárie dos pares de mães/ filhos foi realizada utilizando o índice CPOS e ceos modificados, onde se avalia, dentre outras, as superfícies hígidas, manchas brancas ativas, manchas brancas inativas, cavidades ativas, cavidades inativas, restaurações, restaurações alteradas e/ou fraturadas, recidivas de lesões de cárie, destruições coronárias, fístulas e hipoplasias ( Fritscher et al.,1998).

A saliva estimulada coletada foi conservada em meio de transporte específico, para posteriormente se fazer o isolamento e genotipagem de estreptococos mutans*, no laboratório do Specialized Caries Research Center da Universidade do Alabama, USA.

(*Técnica citada por Caufield, P.W. et al.. Initial acquisition of mutans streptococci by infants: evidence for a discrete window of infectivity. J. Dent. Res.,v.72 p.37- 45,1993 e Caufield, P. W. Dental caries - a transmissible and infectious disease revisited: a position paper. American Academy of Pediatric Dentistry. p.491 a 498, 1997) 


\section{Resultados e discussão}

Para um maior entendimento os resultados serão

Filhos adotivos

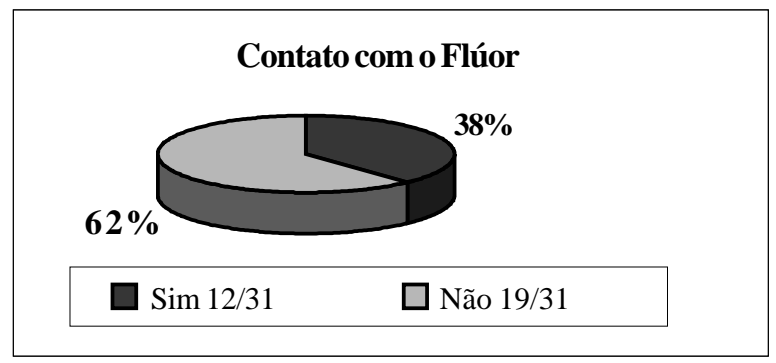

apresentados na forma de gráficos e tabelas e serão discutidos na seqüência.

Filhos naturais

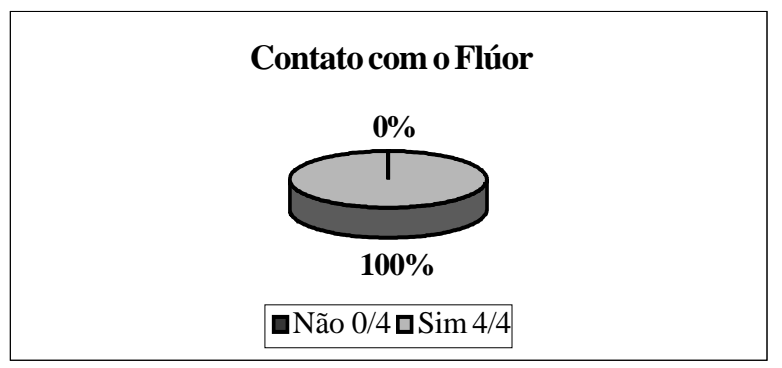

Gráficos 1 e 2 - A freqüência de contacto com o flúor dos filhos adotivos e naturais.

Considerando que os filhos adotivos infelizmente não puderam receber o aleitamento materno esabendo o quanto este é muito mais que nutrição, é oferecer qualidade de vida à criança, foram apresentados os resultados com relação apenas a amamentação artificial dessas crianças. Como as mães adotivas não dispunham de leite materno, o correto era ter introduzido o leite bovino, tipo C, fervido numa diluição a $1 / 2$ até $o$ bebê completar 30 dias, passando a 2/3 até o terceiro mês de vida. Essa diluição deveria ser feita com mucilagem (água de arroz ou água de aveia). Quando o bebê chegasse aos 6 meses este deveria passar a ter três refeições principais, com a introdução de outros alimentos, e complementar sua alimentação com até duas ingestões de leite com $250 \mathrm{ml}$ diários. O leite servido deveria ser do tipo $\mathrm{C}$, fervido e puro, sem a

Filhos adotivos

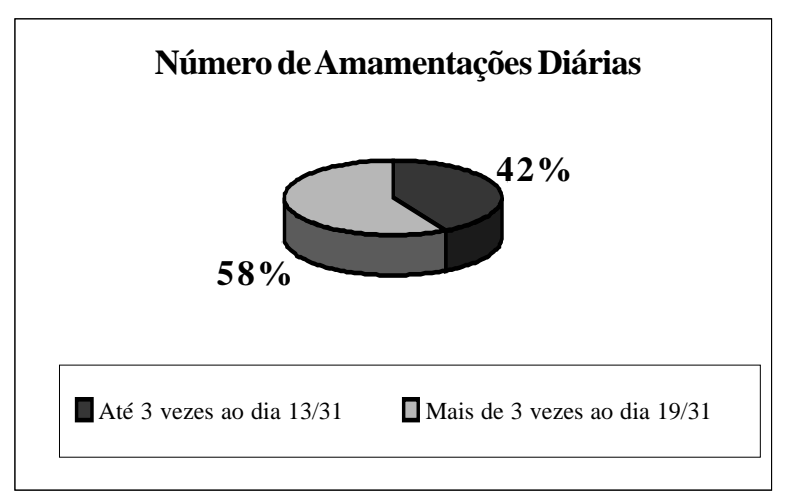

adição de açúcar, achocolatados ou farinhas, de preferência utilizando-se xícara ou copo. Mas isso não foi observado,uma vez que $58 \%$ dos filhos nesse período apresentavam uma freqüência de amamentação considerada cariogênica por ultrapassar três vezes de ingesta ao dia, sendo que $99 \%$ dessas mamadeira eram adoçadas com açúcar, o que potencializava sem dúvida alguma, a cariogenicidade da alimentação dos filhos adotivos e naturais (Gráficos 3,4, 5,6,7 e 8 ).

É sabido que o consumo freqüente de sacarose é um dos fatores determinantes na instalação das doenças bucais, cárie e periodontal e que hábitos alimentares aprendidos na infância dificilmente serão modificados posteriormente. É interessante ressaltar que não se observou qualquer diferença significante com relação às mães e seus filhos adotivos e naturais.

\section{Filhos naturais}

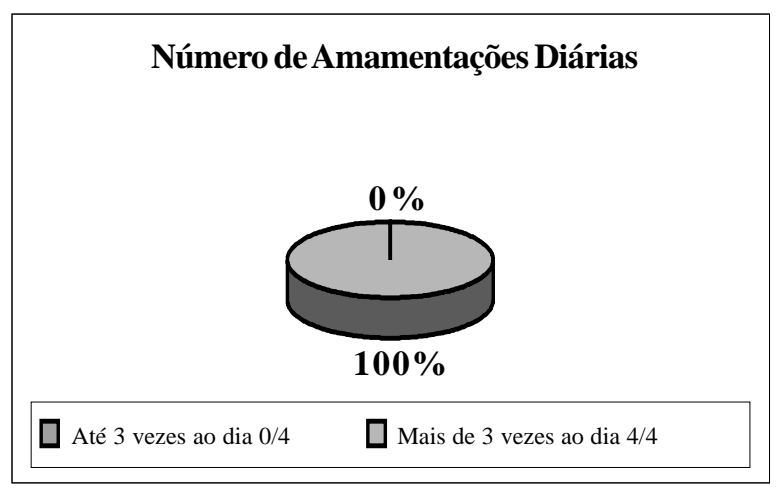

Gráficos 3 e 4 - Relação percentual do número de amamentações diárias do filho adotivo e natural. 
Filhos adotivos

Uso de Açúcar na Mamadeira

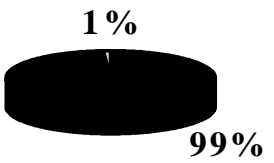

Com açúcar 30/31

$\square$ Sem açúcar $1 / 31$
Filhos naturais

Uso de Açúcar na Mamadeira

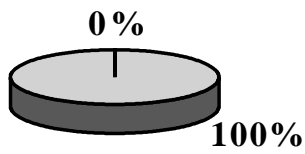

$\square$ Com açúcar $4 / 4$

$\square$ Sem açúcar $1 / 31$

Gráficos 5 e 6 - Relação percentual da utilização do açúcar na mamadeira natural dos filhos adotivos e naturais.

Por outro lado, existem uma enormidade de variáveis envolvidas na relação entre cárie dentária e consumo de açúcares, que são a quantidade ingerida, a freqüência de ingestão, a concentração de açúcar no alimento e o tipo de açúcar ingerido. Mas especificamente com relação ao momento do uso, assume importância particularmente nesse período da vida, a ingestão de alimentos durante o sono. Quando os alimentos são ingeridos durante o sono o desafio cariogênico aumenta sensivelmente, já que eles permanecem

Filhos adotivos

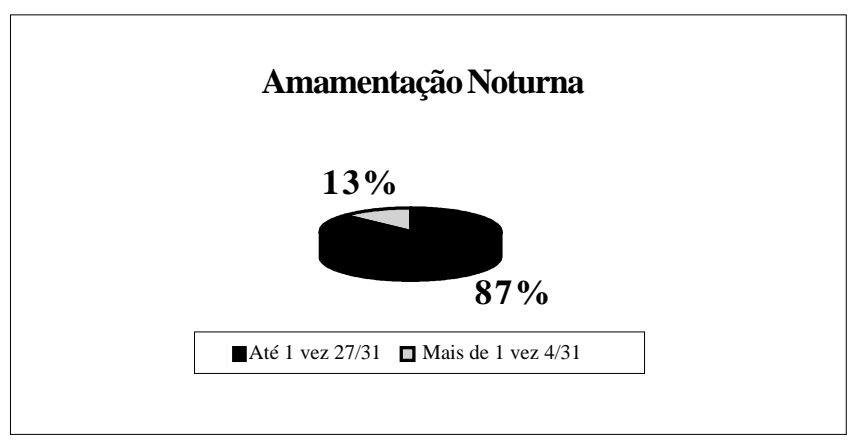

mais tempo na boca, devido à diminuição dos reflexos de deglutição e movimentos musculares, além disso a ação protetora da saliva está muito diminuída em função da redução do fluxo salivar. Dessa forma, os alimentos ficam retidos na boca durante um tempo maior. Como se verifica nos gráficos 7 e 8 , entre as crianças avaliadas é comum a ingestão de alimentos durante o sono através da mamadeira, sendo que a literatura relata a relação positiva entre a amamentação noturna e o aparecimento de lesões de cárie em crianças.
Filhos naturais

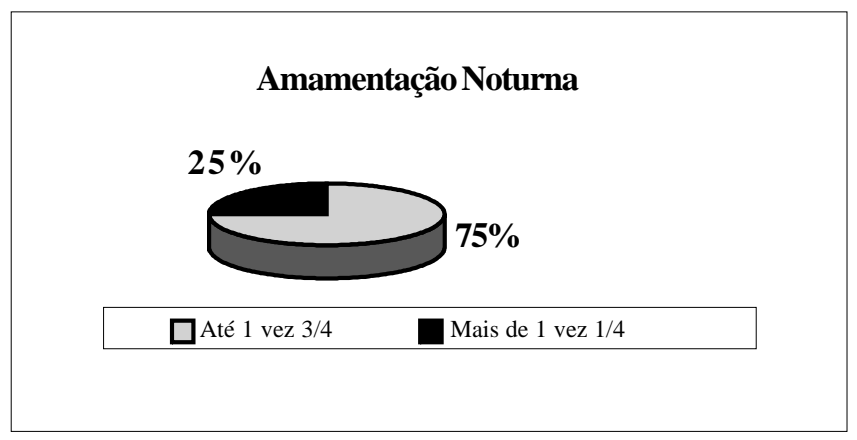

Gráficos 7 e 8 - Relação percentual da freqüência da amamentação noturna das mães para com seus filhos adotivos e naturais 
Filhos adotivos

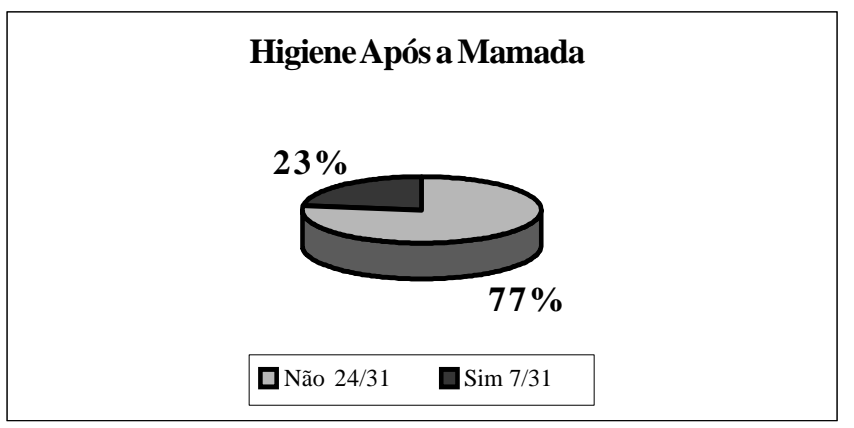

Filhos naturais

\section{Higiene Após a Mamada}

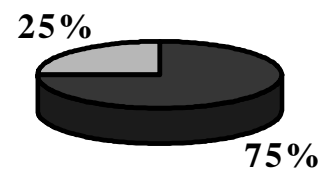

Não 3/4

Gráficos 9 e 10 - Relação percentual da freqüência dos hábitos higiene bucal após as mamadas diárias dos filhos adotivos e naturais

Por outro lado supõe-se que as mães sejam orientadas quanto à higiene bucal de seu bebê, sendo que esta deve ser realizada diariamente e introduzida após o nascimento da criança numa freqüência de $2 \mathrm{a}$ 3 vezes ao dia, dando maior ênfase a higienização da noite, antes de dormir. Para essa primeira limpeza, devese utilizar gaze ou ponta de fralda embebida em água filtrada ou fervida. Com o aparecimento dos primeiros dentes decíduos, em torno de seis meses de vida, devese iniciar a higiene com escova dental pequena e macia, utilizando-se dentifrício fluoretado, numa quantidade semelhante ao tamanho de uma lentilha. Mas infelizmen- te como é visto nos gráficos 9 e 10 , aproximadamente $75 \%$ das mães não realizaram a higiene bucal de seus filhos tanto dos adotivos como dos naturais.

Por outro lado, mesmo com alguns desses fatores relacionados ao aparecimento da doença cárie exacerbados, ou seja, dieta cariogênica e falta de higiene bucal, os filhos adotivos avaliados não apresentaram cárie e mais, aqueles que apresentaram, tinham menos de 25\% das superfícies dentárias atingidas por cárie. Em contrapartida, a maioria das mães adotivas avaliadas apresentavam um elevado índice de cárie CPOS modificado.(tabela 1).

Tabela 1 - Relação percentual da presença de superfícies dentárias atingidas - cariadas, perdidas ou obturadas, CPOS e ceos modificados, das mães e de seus filhos adotivos e naturais

\begin{tabular}{c|c|c|c|c}
\hline \multicolumn{2}{c|}{ CPOS Mães } & \multicolumn{2}{c|}{ CPOS Filhos } & ceos \\
\hline \% das superfícies & $\mathbf{N}^{\mathbf{0}}$ de mãe & \% das superfícies & $\mathbf{N}^{\mathbf{0}}$ de filhos & $\mathbf{N}^{\mathbf{o}}$ de filhos \\
\hline $0-25 \%$ & $01(5,5 \%)$ & $\begin{array}{c}<25 \% \\
>25 \%\end{array}$ & $\begin{array}{c}26(100 \%) \\
0(0 \%)\end{array}$ & $5(23 \%)$ \\
\hline $26-50 \%$ & $06(33,3 \%)$ & - & & \\
\hline $51-75 \%$ & $07(38,8 \%)$ & - & & \\
\hline $76-100 \%$ & $04(22,2 \%)$ & - & & \\
\hline TOTAL & 18 & TOTAL & & \\
\hline
\end{tabular}


Tabela 2.1 - Relação percentual das atitudes/comportamento das mães para com seus filhos adotivos

\begin{tabular}{l|c|c|c}
\hline \multicolumn{1}{c|}{ Hábitos Maternos } & Sim & Não & Total \\
\hline Sopra o Alimento para a Criança & $19(62 \%)$ & $12(38 \%)$ & 31 \\
\hline Prova o Alimento para a Criança & $15(48 \%)$ & $16(52 \%)$ & 31 \\
\hline Beijo na Boca da Criança & $09(29 \%)$ & $22(71 \%)$ & 31 \\
\hline Limpa o Bico com a Própria Boca & $2(6 \%)$ & $29(94 \%)$ & 31 \\
\hline
\end{tabular}

Tabela 2.2 - Relação percentual das atitudes/comportamento das mães para com seus filhos naturais

\begin{tabular}{l|c|c|c}
\hline \multicolumn{1}{c|}{ Hábitos Maternos } & Sim & Não & Total \\
\hline Sopra o Alimento para a Criança & $1(25 \%)$ & $3(75 \%)$ & 4 \\
\hline Prova o Alimento para a Criança & $1(25 \%)$ & $3(75 \%)$ & 4 \\
\hline Beijo na Boca da Criança & $1(25 \%)$ & $3(75 \%)$ & 4 \\
\hline Limpa o Bico com a Própria Boca & $0(0 \%)$ & $4(100 \%)$ & 4 \\
\hline
\end{tabular}

Sendo a cárie uma doença multifatorial poderse-ia dizer que o fator MICROBIOTA CARIOGÊNICA não se estabeleceu no período da janela da infectividade de cárie por não ter ocorrido a transmissão/infecção dos microorganismos cariogênicos das mães adotivas e seus filhos, mas os hábitos relacionados a esta transmissão/infecção do microorganismos cariogênico das mães para seu filhos existiram com grande relevância (Tabelas 2.1 e 2.2).

Esse fato finalmente é explicado pela existência de um baixo percentual de genótipos homólogos entre as mães e seus filhos adotivos, o que estão de acordo com a literatura, que afirma que as linhagens de estreptococos do grupo mutans são transmitidas da mãe para o seu filho natural, ou seja, a aquisição de estreptococos do grupo mutans em humanos segue a linha materna (Tabela 3).

Inclusive, por que não se pensar na introdução de cepas não-maternas de $S$. mutans e/ou outros microorganismos indígenas, que sejam menos viru-lentos, antes do início da irrupção dos primeiros dentes decíduos na cavidade bucal de um bebê? 
Tabela 3 - Identificação dos genótipos de amostras de estreptococos do grupo mutans isoladas da cavidade bucal de mães e de seus filhos adotivos e naturais

\begin{tabular}{|c|c|}
\hline Mãe e Filhos & Genótipo de S.mutans - AP-PCR \\
\hline Mãe & - \\
\hline Mãe & A B \\
\hline Adotado & $\mathrm{CC}^{\prime}$ \\
\hline Adotado & C \\
\hline Adotado & - \\
\hline Mãe & - \\
\hline Adotado & - \\
\hline Adotado & - \\
\hline Adotado & - \\
\hline Mãe & - \\
\hline Adotado & - \\
\hline Mãe & A B C \\
\hline Adotado & D \\
\hline Adotado & - \\
\hline Mãe & A A'B \\
\hline Adotado & C D \\
\hline Mãe & A B C D \\
\hline Adotado & $\mathrm{E}$ \\
\hline Mãe & $\mathrm{A}$ \\
\hline Adotado & B C \\
\hline Mãe & A B \\
\hline Adotado & $\mathrm{C}$ \\
\hline Adotado & - \\
\hline Mãe & A \\
\hline Adotado & B \\
\hline Mãe & A B \\
\hline Adotado & $\mathrm{A}^{\prime} \mathrm{B}^{\prime}$ \\
\hline Natural & $\mathrm{C}$ \\
\hline Mãe & A \\
\hline Natural & - \\
\hline Adotado & B C \\
\hline Mãe & A B C \\
\hline Adotado & D E \\
\hline Adotado & $\mathrm{F}$ \\
\hline Adotado & D F' \\
\hline Mãe & $\mathrm{A} \mathrm{A}^{\prime} \mathrm{B}$ \\
\hline Adotado & C D \\
\hline Adotado & A A $A^{\prime} B C$ \\
\hline Adotado & C D E \\
\hline Mãe & A \\
\hline Adotado & A \\
\hline Adotado & A B \\
\hline Mãe & A B C \\
\hline Adotado & D \\
\hline Adotado & D E \\
\hline Natural & $\mathrm{B}$ \\
\hline Mãe & $\mathrm{A}$ \\
\hline Adotado & B \\
\hline Natural & C D \\
\hline Mãe & A B C D \\
\hline Adotado & $\mathrm{E}$ \\
\hline Adotado & B E \\
\hline
\end{tabular}

\section{Conclusões}

- Os genótipos homólogos de estreptococos do grupo mutans entre as mães e seus filhos adotivos apareceram em apenas $19 \%$ dos filhos adotivos (apenas 6 dos 31 filhos adotivos)

- $81 \%$ dos filhos adotivos foram colonizados por estreptococos do grupo mutans não igualados aos de sua mãe adotiva e muitos não tinham cárie, e, se a possuíam, a cárie estava presente em $<25 \%$ de superfícies dentárias.

- Dos 4 filhos naturais, apenas 3 amostras foram analisadas e 1 apresentou genótipos homólogos ao de sua mãe. O número de amostras foi muito baixo para possibilitar algum tipo de discussão e/ou conclusão a respeito.

\section{REFERÊNCIAS}

1. ALALUUSUA, S.; RENKONEN, O. V. Streptococcus mutans establishment and dental caries experiences in children from 2 to 4 years old. Scand J Dent.Res, v.91, p.453-57,1983.

2. ALALUUSUA, S.; NYSTRÖM, M. GRÖNROOS, L.; PECK, L. Caries-related microbiological findigs in a group of teenagers and their parents. Caries Res., v.23, p.49-54, 1989.

3. ARAUJO, F. B. Dente erupcionado, deve ser selado?. In: Atualização na clínica odontológica - $16^{\circ}$ Congresso Paulista de Odontologia. São Paulo: Artes Médicas, 1994, 365p, p.197203.

4. ARAUJO, F. B.; FIGUEIREDO, M.C. Promoção de saúde em odontopediatria - In: KRIGER, L., coord. Aboprev - Promoção de Saúde Bucal. São Paulo, Ed. Artes Médicas, 1997. Cap.13, p.283-348.

5. BERKOWITZ, R. J. e JORDAN, H. V. Similarity of bacteriocins of Streptococcus mutans from mother and infant. Archs. Oral Biol.,v. 20, p.725-30, 1975

6. BERKOWITZ, R. J.; JONES, P. Mouth - to - mouth transmission of the bacterium streptococcus mutans between mother and child. Archs. Oral Biol., v.30, n.4, p.377-9, 1985

7. BERKOWITZ, R. J.; TURNER, J.GREEN, P. Maternal salivary levels of Streptococus mutans and primary oral infection of infants. Archs.Oral Biol., v.26, p.147-9, 1981.

8. BRUN, E. Preventing dental caries: breaking the chain of transmission. J. Am. Dent. Assoc., v.123,n.6,p.55-9, 1992. 
9. BUISCHI, L. Salivary streptococcus mutans and caries prevalence in Brazilian schoolchildren Comm Dent Oral Epid, v.17, n.1, p.28-30, 1989.

10. BURNET, G. W.; SCHERP, H. W.; SCHUSTER, G. S. Microbiologia oral e doenças infecciosas. In: Trad. Wilson Chagas de Araújo et al. 4. ed., p.8, 1978.

11. CARLSSON, J., GRAHNEN, H.; JONSSON, G. Lactobacilli and Streptococci in the mouth of children. Caries Res., v.9, p.333-9, 1975.

12. CARLSSSON, J., Absence of various types of nonhaemolytic streptococci in dental plaque and in other sites of the oral cavity in man. Odontol Revy., v.18, p.55-74, 1967.

13. CATALANOTTO, F. A.; SHKLAIR, I. L.; KEENE, H. J. Prevalence and localization of Streptococcus mutans in infants and children. J Am. Dent. Assoc.,v.91, p.606-9,1975.

14. CAUFIELD, P. W.; RATANARRIDAKUL, K.; ALLEN, D. N. CUTTER, G. R. Plasmid - containing strains of Streptococcus mutans cluster within family and racial cohorts: implications in natural transmission. Infect. Immun., v.56, p.3216 -20, 1988.

15. CAUFIELD, P. W., LI, Y., DASANAYAKE, A. P. Initial acquisition of mutans streptococci by infants: evidence for a discrete window of infectivity. J. Dent. Res., v.72, p.37-45,1993.

16. CAUFIELD, P.W. The fidelity of initial acquisition of mutans streptococci by infants from their mothers. J. Dent. Res, v. 74, n. 2, p. 681-5, Feb.1995.

17. CAUFIELD, P. W.; CHILDERS, N. F.; ALLEN, D. N.; HANSEN, J. B. Plasmids in streptococcus mutans: Usefulness as epidemiological markers and association with mutacins. In: HAMAM, S.; MICHALEK S.; KIYONO, H.; MENAKER, L.; MCGHEE, J.; editors Proceedings of an international conference on celular, molecular and clinical aspects of streptococcus mutans. 1985 sept 18-20, Birmingham (AL). New York (NY): Elsevier Science Publishers, p.217-23.

18. CAUFIELD, P. W.; CUTTER, G. R., DASANAYAKE, A. P.; Initial Acquisition of Mutans Streptococci by Infants: Evidence for a Discrete Window of Infectivity, J. Dent.Res., v.72, n.1, p. 37-45, Jan.1993.

19. CAUFIELD, P. W.; WALKER, T. Genetic diversity Within Streptococcus mutans evident by chromosomal DNA Restriction fragment length poly morphisms. J. Clin. Microbiol, v.27, p. 274-8, 1989.

20. CAUFIELD, P. W.; WANNEMUEHLER, Y. M.; HANSEN, J. B. Familial clustering of streptococcus mutans cryptic plasmid strans in a dental clinic population. Infect Immun.,v.38, p.785-7, 1982.

21. CURY, J. A. Uso do Flúor. In: BARATIERI,L. N. et al. Dentística: Procedimentos preventivos e restauradores. Rio de Janeiro: Quintessence,1989, 509p., p.43-67.

22. DASANAYAKE, A. P.; CAUFIELD, P. W.; CUTTER, G. R.;
STILES, H. M. Transmission of mutans streptococci to infants following short term application of an iodine-NaF solution to mother's dentition. Community Dent. Oral Epidemiol., v 21, n.3, p. 136-142, jun. 1993.

23. DAVEY, A.L.; ROGERS, A.H. Multiple types of the bacterium Streptococcs mutans in the human mouth and their intra-family transmission. Archs. Oral Biol., v.29, n.6, p.45360, 1984.

24. EMILSON, C. G. e KRASSE, B. Support for and implications of the specific plaque hypothesis. Scand. J. Dent. Res., v.93, p.6-104, 1985.

25. FIGUEIREDO. M. C ; FRITSCHERA. M. G;ARAUJO, D. F. Avaliação do CPOS modificado, do índice de placa visível e de sangramento gengival em 30 pares mãe-filho. CECADE NEWS, v.4, n.1 e 2, p. 35-45, 1996.

26. FITZGERALD, R. J. e KEYES, P. H. Demonstration of the etiologic role of streptococci in experimental caries in the hamster. J. Amer. Dent. Ass., v.61.p.9-19, 1960.

27. GARCIA-GODOY, F. M. Familial caries distribution in human permanent teeth: buccal and lingual pits of first molars. J Pedod, v. 7, p.318, 1983.

28. KEYES, P. H. Recent advances in dental caries research.Bacteriol. Int. Dent. J., v.12, p.443-63, 1962.

29. KEYES, P. H. The infectious and transmissible nature of experimental dental caries. Archs.Oral Biol., v.1, p.304-20, 1960.

30. KILIAN, M; MIKKELSEN, L; HENRICHENSEN, J. Taxonomic study of viridans streptococci: Description of Streptococcus gordonii sp. nov. and emended descriptions of Streptococcus sanguis (White and Niven 1946), Streptococcus oralis (Bridge and Sneath 1982) and Streptococcus mitis (Andrewes and Horder 1906). Int. J. System Bacteriol.v.39, p.471-84, 1989.

31. KLEIN, H. Family and dental disease (DMF) experience in parents and off springs. J. Am. Dent. Assoc. v. 33, p. 735-43, 1946.

32. KÖHLER, B.; BRATHALL, D. Intrafamilial levels of Streptococcus mutans and some aspects of the bacterial transmission. Scan. J. Dent. Res., v.86, p.41, 1978.

33. KÖHLER, B., JONSSON, B.; BRATHALL, D. Effect of caries preventive measures on Streptococcus mutans and lactobacilli in selected mothers. Scand. J. Dent. Res., v. 90, p.102-8, 1982.

34. KÖHLER, B.; ANDRÉEN, I.; BRATHALL, D., JONSSON, B. Preventive measures in mothers influence the establishment of the bacterium Streptococcus mutans in their infants. Archs.Oral Biol., v.28, p.225-31, 1983.

35. KÖHLER, B.; JONSSON, B.; BRATHALL, The earlier the colonization by mutans streptococci, the higher the caries prevalence at 4 years of age. Oral. Microbiol. Immunol, v.3, 
p.14-7, 1988.

36. KÖHLER, B.; ANDRÉEN, I; JONSSON, B. The effect of caries-preventive measures in mothers on dental caries and the oral presence of the bacteria Streptococcus mutans and lactobacilli in their children. Archs. Oral Biol., v.29, n.11, p.879-83, 1984.

37. KÖNÖNEN, E.; JOUSIMIES-SOMER, H.; ASIKAINEN, S. Relationship between oral gram-negative anaerobic bacteria in saliva of the mother and the colonization of her edentulous infant. Oral Microbiol.Immunol., v.7, n.5, p.:273-6, 1992.

38. KOTSANOS, N. e DARLING, A. I. Influence of posteruptive age of enamel on its susceptibility to artificial caries. Caries Res,v. 25, p.241-50, 1991.

39. KOZAY, K., IWAI, I., MIURA, K., Residual contamination of toothbrushes by microorganisms. J. Dent. Child, v. 56, n.3, p.203-4, 1989.

40. KRASSE, B.; KÖHLER, B.; BRATHALL, D.; Preventive Measures in mothers influence the establishment of the bacterium streptococcus mutans in their infants. Archs Oral Biol., v. 3, p. 225-31, 1983.

41. KULKARNI, G. V.; CHAN, K. H.; SANDHAN, H. J. An investigation into the use of restriction endonuclease analisys for yhe stredy of transmission of mutans streptococci. J. Dent. Res. v.68, p.1155-61, 1989.

42. LOESCHE, W. J. Chemotherapy of dental plaque infections. Oral Sci. Ver., v.9, p.65-107, 1976-1977.

43. MALTZ, M.; CARVALHO, J. Diagnóstico da doença cárie. In: ABOPREV: Promoção de Saúde Bucal, São Paulo: Artes Médicas, 1997.475p, p.69-91.

44. MASUDA, N; SHIMAMOTO, T.; KITAMURA, K.; SOBUE, S.; HAMADA, S.; Transmission of streptococcus mutans in some selected families. Microbios, v.44, p.223-32, 1985.

45. McDONALD, R.; AVERY, D. Dentistry for the child and adolescent. St Louis: Mosby, 1978, p. 118-119.

46. NEVES S. V. de P.- Adoção Outro Final Feliz - Revista Pais \& Filhos, Edit. Abril, Março, 1996

47. ROGERS, A.H. The source of infection in the intratamilial transter of streptococcus mutans. Caries Res., v.15, p.2631,1981 .

48. SOUZA, F. B. Doença cárie: nem infecciosa, nem transmissível. Revista daABOPREV,Abr./mai./jun., p. 9, 1995.

49. STILES, H. M.; MEYERS, R.; BRUNELE, J. A.; WITTIG, A. B. Occurence of Streptococcus mutans and Streptococcus Sanguis in the oral carity and feces of young children. In: Stiles, H. M.; LOESCHE, W.J.; O’BRIEN, T.C.; eds. Proceedings, microbial aspects of dental caries. Vol. I. Supp.; Microbiolosy Abstracts. New York: Information Retrieval Inc., 187-199.

50. SVANBERG, M. Contamination of toothpaste and toothbrush by Streptococcus mutans. Scand. J. Dent. Res., v.86, p.412-4, 1978.

51. TAPPUNI, A. R.; CHALLACOMBE, S. J. Distribution and isolation frequency of eight streptococcal species in saliva from predentate and dentate children and adults. J. Dent. Res., v. 72, n.1, p.31-6, Jan, 1993

52. TENOVUO, J.; HAKKINEN, P.; PAUNIO, P.; EMILSON, CG. Effects of chlorhescidine - flavoride gel treatments in children. Caries Res., v.26, n.4, p.275-280. 1992

53. THIBODEAU, E. A. e O’SULLIVAN, D. M. Salivary mutans streptococci and incidence of caries in preschool children. Caries Res., v.29, p.148-53, 1995.

54. THIBODEAU. Mutans streptococci and caries prevalence in preschool children. Comm Dent Oral Epid.,v.21, p.288, 1993

55. TUUTI, H.; LAHTI, S; HONKALA, E.; MÄÄTTA, T. Comparison of dental caries experience of the parents of caries - free and caries active children. J. Paed. Dent., v.5, p.93-8, 1989.

56. VAN HOUTE, J.; YANOVER, L.; BRECHER, S. Relationship of levels of the bacterium Streptococcus mutans in saliva of children and their parents. Archs. Oral. Biol., v.26, p.381-6, 1981.

57. WEYNE, S. Cariologia. In: BARATIERI,L.N. Dentística: Procedimentos preventivos e restauradores. Rio de Janeiro: Quintessence, 1989, 509p, p.1-42.

58. WHITTLE, J. G. Attendance patterns and dental health of parents and children. Community Dent health, v. 10, n.3, p. 235-42, Sep. 1993.

59. ZICKERT, I.; BRUNELE, J. A.; WITTIG, A. B. Effect of caries preventive measures in children highly infected with the bacterium Streptococcus mutans. Archs. Oral Biol.,v.27,p.861-8, 1982 